\title{
Well Modeling: An Overview
}

\author{
J.C. Roegiers ${ }^{1}$ \\ 1 Mewbourne School of Petroleum \& Geological Engineering, The University of Oklahoma, \\ Norman, Oklahoma - United States \\ e-mail: jc@rmg.pge.ou.edu
}

\begin{abstract}
Résumé - Présentation générale de la modélisation géomécanique des puits de forage — Les conditions régnant à la surface et aux alentours d'un puit de forage influencent souvent le type de développement à choisir ainsi que les procédures d'achèvement à suivre dans le cas particulier d'un champ pétrolier. Les concentrations de contraintes générées par le forage ne sont pas seulement fonction de la géométrie des puits, de la valeur et de l'orientation des contraintes in situ et du comportement de la roche, mais celles-ci sont également affectées par l'intrusion de l'ingénieur.

L'idée maîtresse de cet article est de revoir tout d'abord brièvement les mécanismes classiques de ruptures d'un trou circulaire foré dans une formation isotrope linéaire, tout en essayant d'indiquer les problèmes qui pourraient se révéler sur le chantier. Cet exposé introductif comprend le comportement des forages inclinés et horizontaux. Le cas extrême d'un trou de forage percé, dans un environnement et dans des conditions de réservoir tels que la rupture ne peut être évitée, est ensuite discuté en détail. Cette communication technique considère également l'influence de l'anisotropie de la roche ainsi que les problèmes causés par l'existence de discontinuités dans le massif rocheux. De plus, les phénomènes et l'influence de couplages tels que la poroélasticité et la thermoporoélasticité sont également brièvement discutés.

Finalement, les différentes périodes de la vie d'un réservoir sont considérées. Les simulations couplées permettent en effet d'obtenir une bonne compréhension de la stabilité des forages, de la venue de sables, du dimensionnement des tubages et de leurs ruptures temporelles, de la fracturation hydraulique et des problèmes associés aux réservoirs fracturés. Plusieurs de ces aspects sont ici abordés.
\end{abstract}

Abstract - Well Modeling: An Overview - The conditions prevailing at the wall, or in the neighborhood of a borehole, often influence the selected development scheme of a field, as well as the completion procedures used for each well. The stress concentrations generated by the drilling operation are not only a function of the geometry of the borehole, the magnitude and orientation of the in situ stresses and the reservoir rock behavior, but are also affected by the engineer's intrusion.

This keynote address first succinctly reviews the classical potential failure mechanisms of a circular hole drilled in an elastic isotropic formation, pointing out the associated field problems. This introductory discussion includes stability considerations of far-reaching, as well as horizontal, completions. We then consider the extreme case of a borehole drilled in an environment leading to irremediable failure of the surrounding rock, due either to the low strength of the formation or to adverse in situ stress conditions. The extent of the broken zone is computed and the practical applications discussed in detail. The communication expands then further to include effects of anisotropy, pre-existing discontinuities, as well as coupling phenomena, such as poroelasticity and thermoporoelasticity.

Finally, a number of potential aspects throughout the life of the reservoir are considered. The coupled simulations provide, indeed, insight into wellbore stability, sand production, casing design and timedependent collapse, hydraulic fracturing and naturally fractured reservoirs. Many of those aspects are covered throughout this keynote address. 


\section{INTRODUCTION}

Drilling a well disturbs the pre-existing stress field and generates stress concentrations in its neighborhood. These induced stresses, which are quite different in magnitude and sometimes orientation, as compared to the virgin conditions, are responsible for a number of events, such as borehole stability and fracture initiation. Hence, dependent on their degree of influence, they could affect the overall development of the field.

This keynote address will not discuss in detail the various borehole instability mechanisms, but will limit itself to phenomena that occur near the wellbore and affect further reservoir development plans. In other words, concentrate on local instabilities that might jeopardize the overall goal of being able to produce economically from a particular formation.

In order to approach this problem from a rigorous basis, the state of art in determining the stress concentrations prevailing in the neighborhood of a borehole will first succinctly be reviewed. These, obviously, depend on the geometry of the problem as well as the behavior of the rock formation. Even though in most cases linear elasticity solutions assuming an isotropic medium are good enough as a first approximation, recent technology has developed additional complex solutions that have shed some light on near-wellbore behavior.

\section{BOREHOLES DRILLED PARALLEL TO A PRINCIPAL IN SITU DIRECTION}

In the past, most of the solutions developed for circular openings tacitly assumed that the axis of the hole was parallel to a principal stress component. This approach was acceptable as most boreholes were drilled in a vertical direction and the overburden was most often one of these stress components. In addition, this geometry made the problem two-dimensional as the effect of the longitudinal stress was considered to be negligible.

The following sections summarize the various approaches in chronological order.

\subsection{Pressurized Borehole subject to isotropic lateral stress conditions}

The general expressions for the 3D solution is essentially the same as the one developed for a hollow cylinder, i.e:

$$
\left\{\begin{array}{l}
\sigma_{r}=\frac{p_{2} R_{2}^{2}-p_{1} R_{1}^{2}}{R_{2}^{2}-R_{1}^{2}}+\frac{\left(p_{1}-p_{2}\right) R_{1}^{2} R_{2}^{2}}{\left(R_{2}^{2}-R_{1}^{2}\right) r^{2}} \\
\sigma_{\theta}=\frac{p_{2} R_{2}^{2}-p_{1} R_{1}^{2}}{R_{2}^{2}-R_{1}^{2}}-\frac{\left(p_{1}-p_{2}\right) R_{1}^{2} R_{2}^{2}}{\left(R_{2}^{2}-R_{1}^{2}\right) r^{2}} \\
\sigma_{z}=\frac{P}{\pi\left(R_{2}^{2}-R_{1}^{2}\right)}
\end{array}\right.
$$

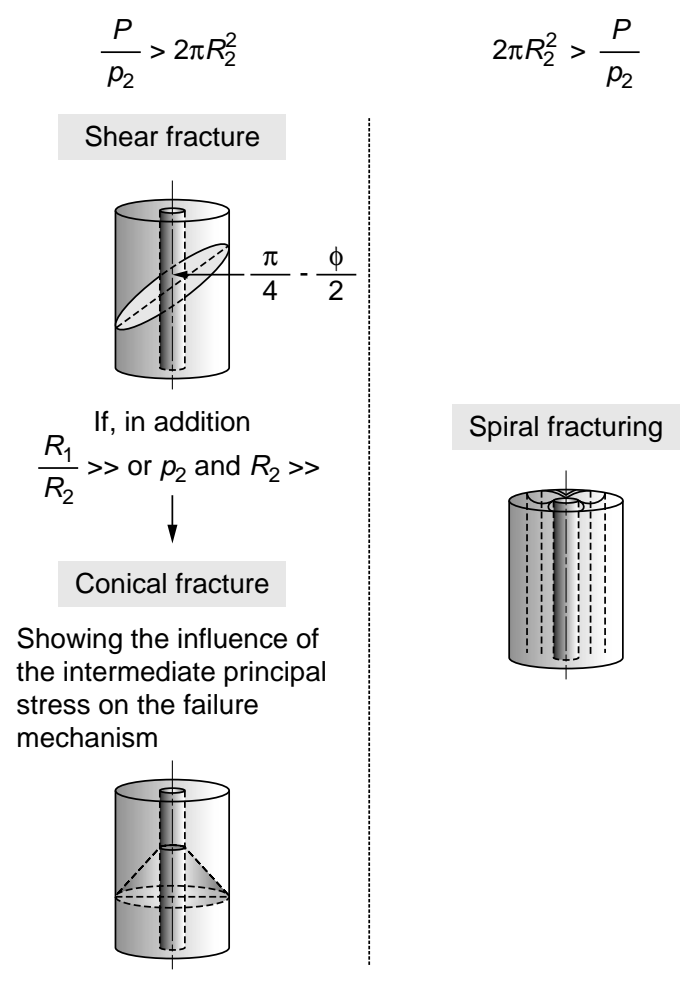

Figure 1

Failure modes for negligible internal borehole pressure.

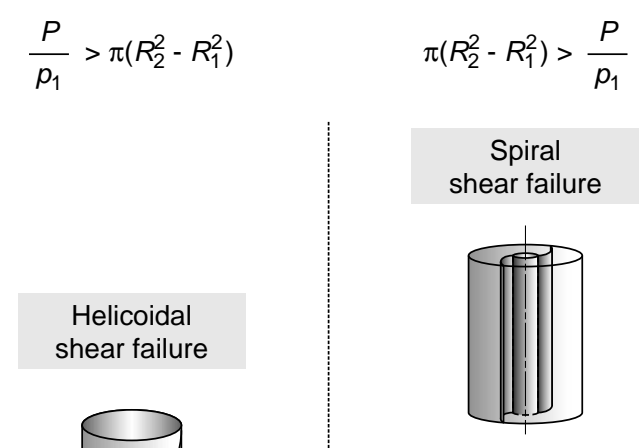

or,

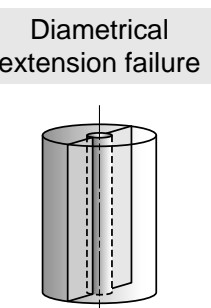

if the tensile failure criterion is reached first

Figure 2

Failure modes for negligible outside pressure. 
where:

$p_{1}=$ internal or mud pressure

$p_{2}=$ external or far-field stress

$P=$ longitudinal, or overburden load in the case of a vertical hole

$R_{1}=$ borehole radius;

$R_{2}=$ external radius

In case of no internal pressure (i.e. drilling with foam or with air), the above expressions simplify and it can easily be shown that three types of failure can result, depending on the following relative values of the input parameters (Fig. 1).

If on the other hand, the external lateral load is negligible, two types of failures can emanate; again, depending on the relative values of the input parameters (Fig. 2).

All of the above failures may jeopardize the borehole stability due to the fact that they will cause unexpected drilling mud losses and may lead to the influx of pore fluids into the wellbore; an obvious potential blowout situation. A temporary loss of mud weight might also lead to wellbore sloughing or even trigger the onset of sanding.

\subsection{Influence of Stress-Dependent Elastic Modulus}

Most rocks exhibit a substantial different Young's modulus in tension than in compression, i.e. $\frac{E_{c}}{E_{t}}$ can reach values as high as 20. Since borehole pressurization leads to tensile circumferential stress values, this dual characteristic should,

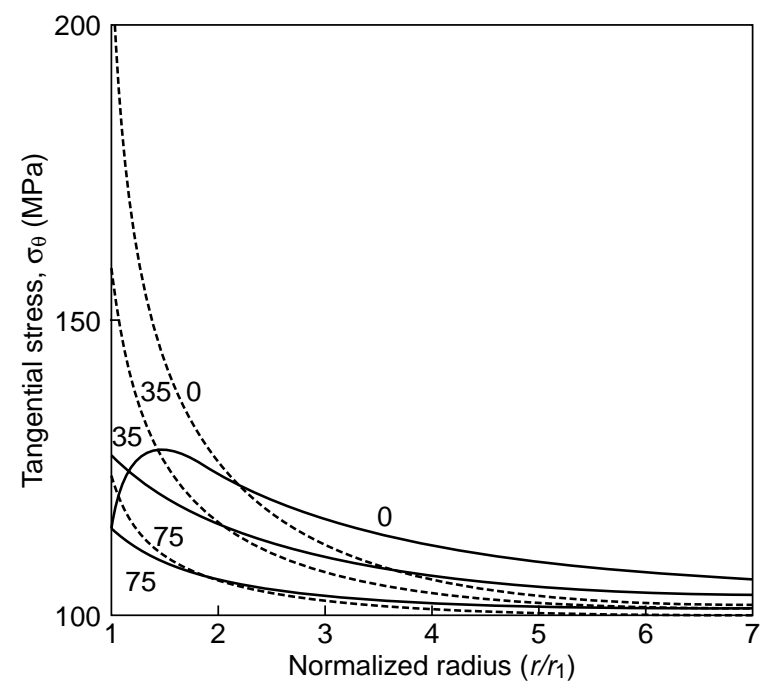

Figure 3

Tangential stress distributions assuming an external pressure of $100 \mathrm{MPa}$ (dashed lines correspond to constant modulus, numbers on the curves correspond to internal borehole pressure in MPa) (after Santarelli et al., 1986). (a)

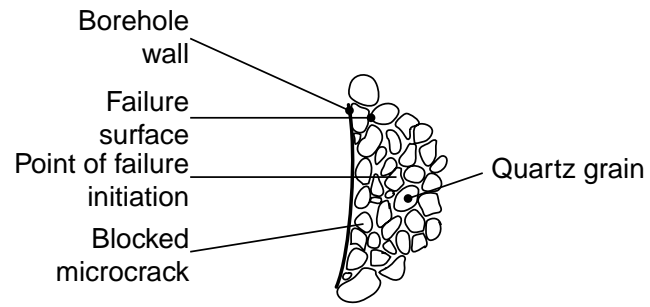

(b)

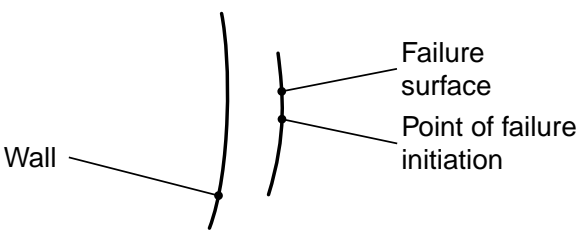

Figure 4.

Schematic failure initiation (after Santarelli and Brown, 1989).

(a) doddington sandstone; (b) gebdykes dolomite.

theoretically, be taken into account. Santarelli et al. (1986), Santarelli (1987), and Santarelli and Brown (1987) considered this case and concluded that this lowers the magnitude of the circumferential stress component at the borehole wall; i.e. it enhances stability. However, more importantly, $\sigma_{\theta ; \max }$ is shifted from the borehole wall to the interior of the rock mass at a distance of approximately $5 \%$ of the borehole diameter (refer to Fig. 3). Even though this seems negligible, the implications are that failure initiates inside the formation (see Fig. 4).

This could explain why most breakouts result from buckling (Germanovich and Roegiers, 1994), rather than shear which is the usual assumption made when interpreting such data in the petroleum industry (refer to Fig. 5).

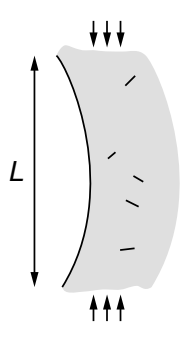

(a)

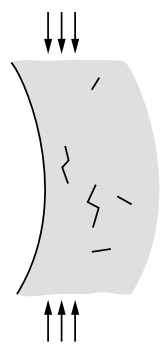

(b)

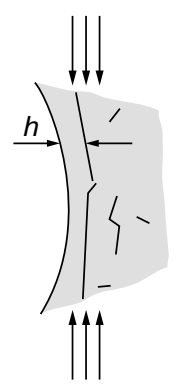

(c)

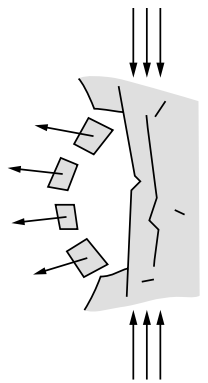

(d)
Figure 5 1994). 


\subsection{Pressurized Borehole Subject to Biaxial Loading}

Generally speaking, isotropic lateral stress conditions are an exception rather than the rule. Tectonic activity and pastgeological events have added stress components in a given orientation, resulting in two different horizontal stress components.

In this case, the general expressions for the 2D solution are given by:

$$
\begin{aligned}
& \sigma_{r}=\frac{Y+X}{2}\left(1-\frac{R_{1}^{2}}{r^{2}}\right)+\frac{Y-X}{2}\left(1-4 \frac{R_{1}^{2}}{r^{2}}+3 \frac{R_{1}^{4}}{r^{4}}\right) \cos 2 \theta+\frac{p_{1} R_{1}^{2}}{r^{2}} \\
& \sigma_{\theta}=\frac{Y+X}{2}\left(1+\frac{R_{1}^{2}}{r^{2}}\right)-\frac{X-Y}{2}\left(1+3 \frac{R_{1}^{4}}{r^{4}}\right) \cos 2 \theta-\frac{p_{1} R_{1}^{2}}{r^{2}} \\
& \tau_{r \theta}=\frac{Y-X}{2}\left(1-2 \frac{R_{1}^{2}}{r^{2}}-3 \frac{R_{1}^{4}}{r^{4}}\right) \sin 2 \theta
\end{aligned}
$$

where:

$Y$ is the far-field stress acting in the direction corresponding

$$
\text { to } \theta=\frac{\pi}{2}
$$

$X$ is the far-field stress acting in the direction corresponding to $\theta=0$;

$\theta$ is measured in the counter-clockwise direction.

It should be pointed out that in high differential stress areas, when either $\frac{P}{Q}$, or $\frac{Q}{P}$ becomes larger than 3 , tension will develop at the borehole wall leading to potential fracturing (refer to Fig. 6). This failure is induced solely by drilling, even though the in situ reservoir conditions are compressive, leading to unusually high mud losses.

\subsection{Influence of Broken Zone}

There are cases where the formation is so weak, or where the in situ stress is so high that the sole fact of drilling a borehole will lead to extensive fracturing. In such a case it is still possible to complete the well, but it is advisable to keep the rubble into place as it will participate to the overall stability, as well as limit the extent of the associated failed zone. If one assumes that both the broken and intact rocks behave as Coulomb materials (with independent cohesion and angles of friction), the following expressions for the extent of the broken zone can easily be derived (Fig. 7):

$$
\begin{aligned}
& \text { If } \sigma_{\theta}>\sigma_{r}: \\
& \qquad R^{*}=R_{1}\left\{\frac{\left(2 p_{2}-S_{o}^{\prime}\right)(1-q)-S_{o}\left(1-q^{\prime}\right)}{\left(1+q^{\prime}\right)\left[p_{1}(1-q)+S_{o}\right]}\right\}^{\frac{1}{q-1}}
\end{aligned}
$$

and, if $\sigma_{r}>\sigma_{\theta}$ :

$$
R^{*}=R_{1}\left\{\frac{\left(S_{o}^{\prime}+2 q^{\prime} p_{2}\right)(1-q)-S_{o}\left(1+q^{\prime}\right)}{\left(1+q^{\prime}\right)\left[p_{1}(1-q)-S_{o}\right]}\right\}^{\frac{q}{1-q}}
$$

where:

$S_{o}, S^{\prime}{ }_{o}$ are the cohesion of the intact and broken rocks, respectively; and

$q, q^{\prime}$ are the tangents of the angle of friction of the intact and broken rocks, respectively).

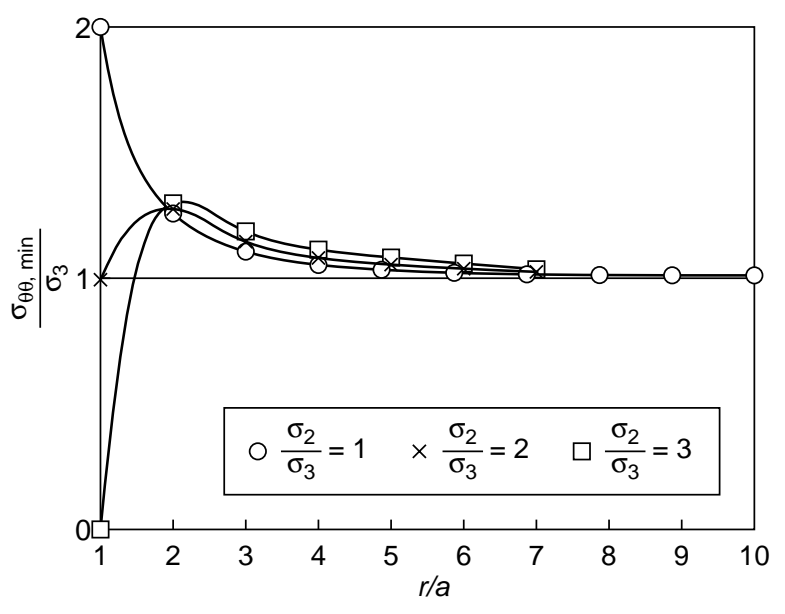

Figure 6

Tangential stress distributions for various in situ stress ratios.

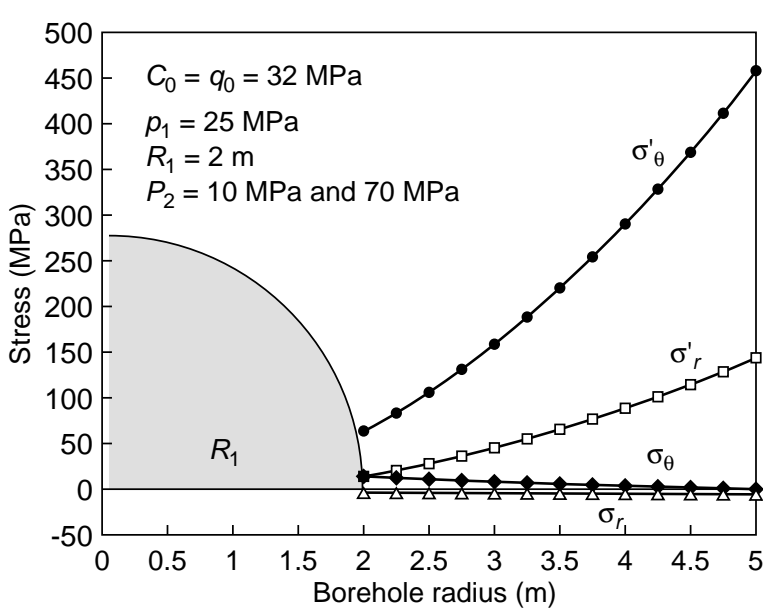

Figure 7

Radial and tangential stresses around the circular opening. 


\subsection{Borehole in Elasto-Plastic Rock with Dilatancy}

This is again the case where the strength of the rock is overcome, but the formation flows plastically rather than failing in a brittle mode. Following general plasticity concepts, the extent of this plastic zone can be obtained using the following formula:

$$
R^{*}=R_{1}\left\{\frac{2}{N_{\phi}+1} \cdot \frac{S_{o}+\left(N_{\phi}-1\right) p_{2}}{S_{o}+\left(N_{\phi}-1\right) p_{1}}\right\}^{\frac{1}{N_{\phi}-1}}
$$

where: $N_{\phi}=\frac{1+\sin \phi}{1-\sin \phi}$

\subsection{Borehole in Strain Softening Rock}

The residual strength which can be mobilized from the postpeak behavior of rocks also contribute to the overall stability of the borehole. This time, three separate regions coexist, as seen in Figure 8:

In the case of $\sigma_{\theta}<\sigma_{r}$, the extent of the broken zone, $R^{\prime}$, is given by:

$$
R^{\prime}=R_{1}\left\lceil\frac{C R^{\prime A}+D R^{\prime}}{(k-1) p_{1}}\right\rceil^{\frac{1}{k-1}}
$$

and its value can only be obtained via an iterative process.

\section{INCLINED BOREHOLES}

More recently, the oil and gas industry has been drilling in more difficult environments such as naturally-fractured reservoirs, lenticular reservoirs, etc. In addition, in offshore situations and remote locations, multiple lateral completions are preferred to minimize human intrusion and limit the encroachment on nature. For all those reasons, the industry started to drill highly inclined and even horizontal wells that were kicked off from a vertical "starter borehole". Early (accidental?) successes in production increase rapidly put pressure on everyone in the industry to consider these alternatives without realizing that inclined boreholes were true 3D problems (refer to Fig. 9), raising the potential problems by one order of magnitude. Unusually high percentages of failures, at least at the beginning of this "fashion", testify to this statement.

However, since this pioneering time, the industry has started to realize the importance of geomechanics and rigorous theoretical developments have been introduced.

\subsection{Isotropic Formations}

For an arbitrarily oriented borehole, the mapping of the stress tensor from the global in situ coordinate system to the local borehole coordinate system is given by solving the following system of equations:

$$
\left\{\begin{array}{l}
\sigma_{x} \\
\sigma_{y} \\
\sigma_{z} \\
\tau_{x} \\
\tau_{y} \\
\tau_{z}
\end{array}\right\}=\left[\begin{array}{lll}
\sin ^{2} \beta & \cos ^{2} \beta \cos ^{2} \alpha & \cos ^{2} \beta \sin ^{2} \alpha \\
0 & \sin ^{2} \alpha & \cos ^{2} \alpha \\
\cos ^{2} \beta & \sin ^{2} \beta \cos ^{2} \alpha & \sin ^{2} \beta \sin ^{2} \alpha \\
0 & -\sin \alpha \cos \alpha \sin \beta & \sin \alpha \cos \alpha \sin \beta \\
-\sin \beta \cos \beta & \sin \beta \cos \beta \cos ^{2} \alpha & \sin \beta \cos \beta \sin ^{2} \alpha \\
0 & -\sin \alpha \cos \alpha \cos \beta & \sin \alpha \cos \alpha \cos \beta
\end{array}\right]\left\{\begin{array}{l}
\sigma_{v}^{\prime} \\
\sigma_{H \mathrm{MAX}}^{\prime} \\
\sigma_{h \min }^{\prime}
\end{array}\right\}
$$
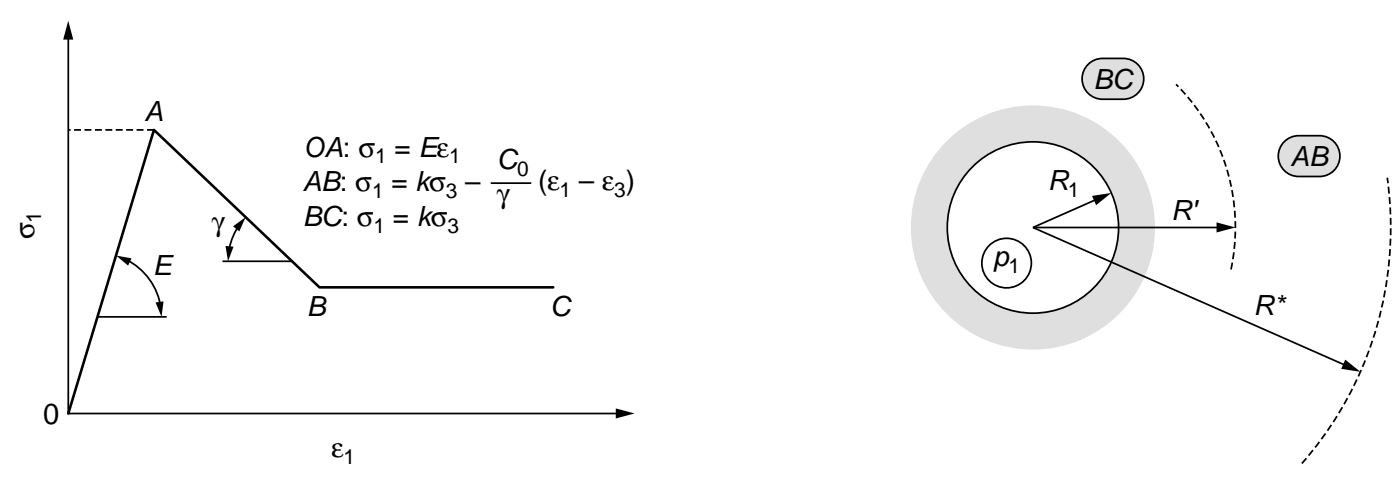

Figure 8

Strain softening material. 
where:

$\sigma_{v}^{\prime}, \sigma_{H \mathrm{MAX}}^{\prime}$, and $\sigma_{\min }$ are the effective vertical, effective major horizontal and effective minor horizontal stresses, respectively;

$\beta$ is the borehole inclination;

$\alpha$ is the borehole azimuth, measured from $\sigma_{H \mathrm{MAX}}^{\prime}$ orientation.

The above expressions are then used to compute the local stress field in a cylindrical coordinate system, which then simplify at the borehole wall to become:

$$
\left\{\begin{array}{l}
\sigma_{r}=p_{1} \\
\sigma_{\theta}=\sigma_{x}+\sigma_{y}-2\left(\sigma_{x}-\sigma_{y}\right) \cos 2 \theta-4 \tau_{x y} \sin 2 \theta-p_{1} \\
\sigma_{z}=\sigma_{z}^{o}+2\left(\sigma_{x}-\sigma_{y}\right) \cos 2 \theta-4 \tau_{x y} \sin 2 \theta \\
\tau_{r \theta}=o \\
\tau_{r z}=o \\
\tau_{\theta z}=2\left(-2 \tau_{x y} \sin \theta-\tau_{x y} \cos \theta\right)
\end{array}\right.
$$

where $\theta$ is the angle between the local $x$-axis and the coordinate of the point considered for stress computation.

The major difference between boreholes drilled parallel to one of the principal stress directions resides in the fact that one of the shear stress components, i.e. $\tau_{\theta z}$, is finite. Practically speaking, this means that the stress tensor orientation at the borehole wall is different than the stress orientation prevailing in the reservoir. The implications are enormous, especially when considering hydraulic fracturing stimulation. Indeed, the fracture initiation direction will differ from its propagation attitude; i.e. the fractures are not any longer planar and re-orient themselves as they grow away from the borehole. This can cause early screen-outs, depending on the sharpness of this bend. In addition, the maximum fracture width occurs away from the borehole wall. This is a typical example where the conditions prevailing in the neighborhood of the borehole play a critical role in the overall completion scheme adopted for reservoir development.

\subsection{Anisotropic Formations}

More recently, the generalized plane strain solution for an inclined well is an anisotropic formation was developed by Ong (1994) (refer to Fig. 10). In the most general case, when the anisotropy orientation is independent of the stress anisotropy orientation, logic and engineering common sense do not provide insight in striving for the optimum solution. For example, some specific input data might dictate a lowering of the mud pressure to increase borehole stability.

\subsection{Influence of Coupling}

A number of mechanisms, such as fluid flow and temperature, are affected by the drilling of a borehole due to the fact that pre-existing equilibrium conditions have been disturbed. In the past, those effects were considered independently; the solution of the fluid flow problem gave pore pressure distributions and boundary conditions then used as input values to the mechanical problem. Such iterations, if convergent, led to a final solution. By the same token, temperature differences between the borehole fluids and the reservoir conditions were believed to only introduce an additional thermal expansion of the rock formation.

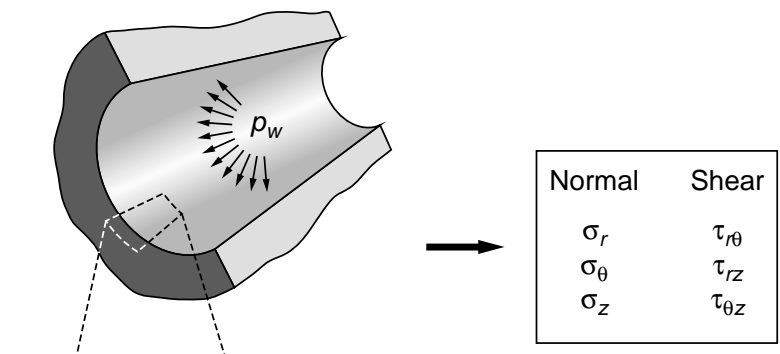

Figure 9

3D stress distribution around an inclined borehole.

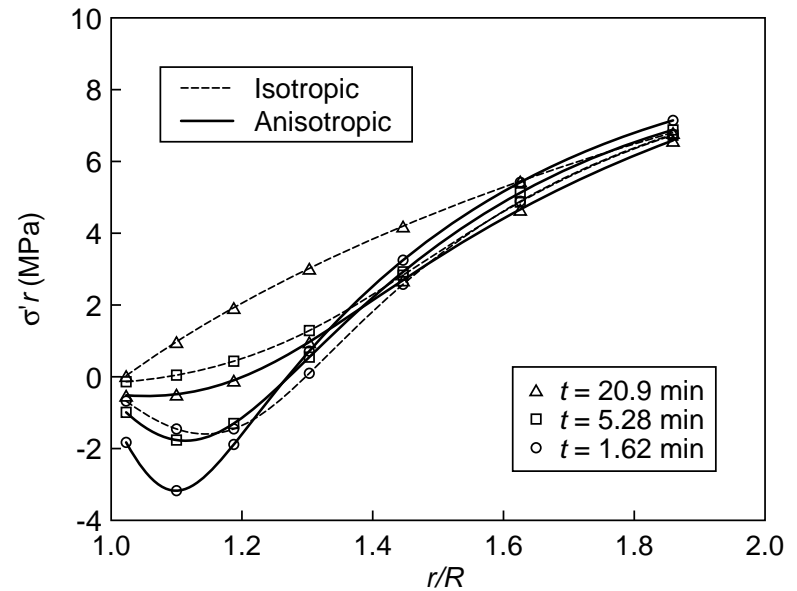

Figure 10

Influence of formation anisotropy (after Ong, 1994). 


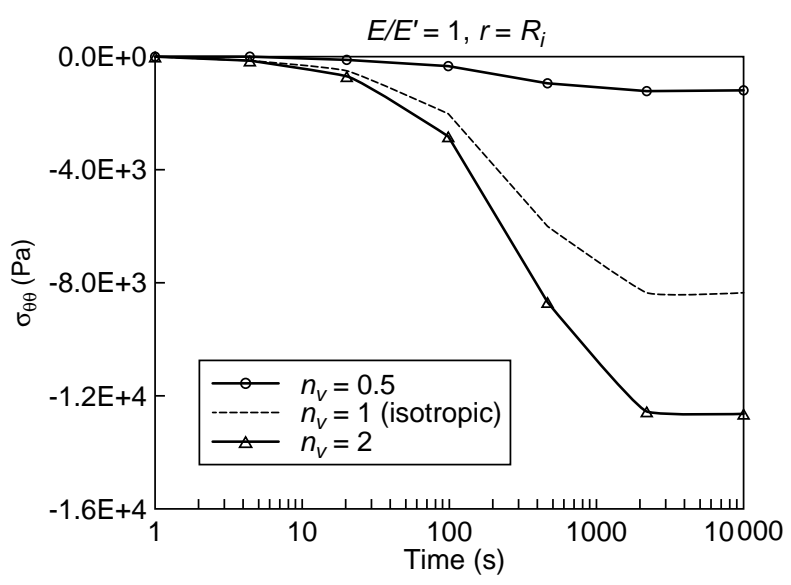

Figure 11

Influence of poroelastic anisotropy (after Ong, 1994).
In 1940, Biot was the first one to point out the strong coupling existing in porous media between the fluid flow portion and the mechanical deformations. He introduced coupled equations applicable to 1D consolidation. It took almost half a century for the petroleum industry to realize the importance of poroelasticity; and, only recently, has some field evidence of poroelastic effects been outlined.

Due to the inherent additional diffusion phenomenon, timedependent effects start do dominate depending on the relative importance of the formation permeability $v s$. its diffusivity (refer to Fig. 11). Hence, in low permeability reservoirs, for example, instantaneous pore pressure differences will diffuse over a certain period of time. If one considers that permeability of a formation is affected by the confining pressure, one can easily understand that this diffusion will usually be anisotropic, leading to cross-flows and potential reverse of borehole wall deformation directions.
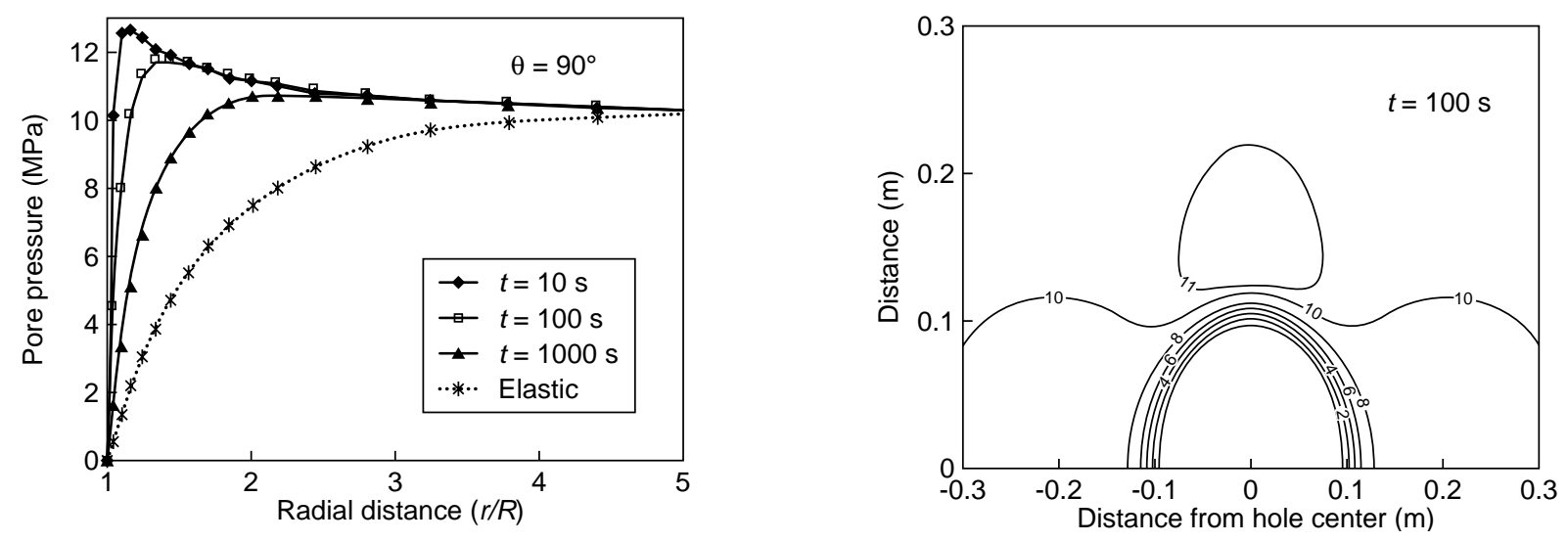

Figure 12

Pore pressure distribution in dual-porosity poroelastic solution (after Zhang, 2002).
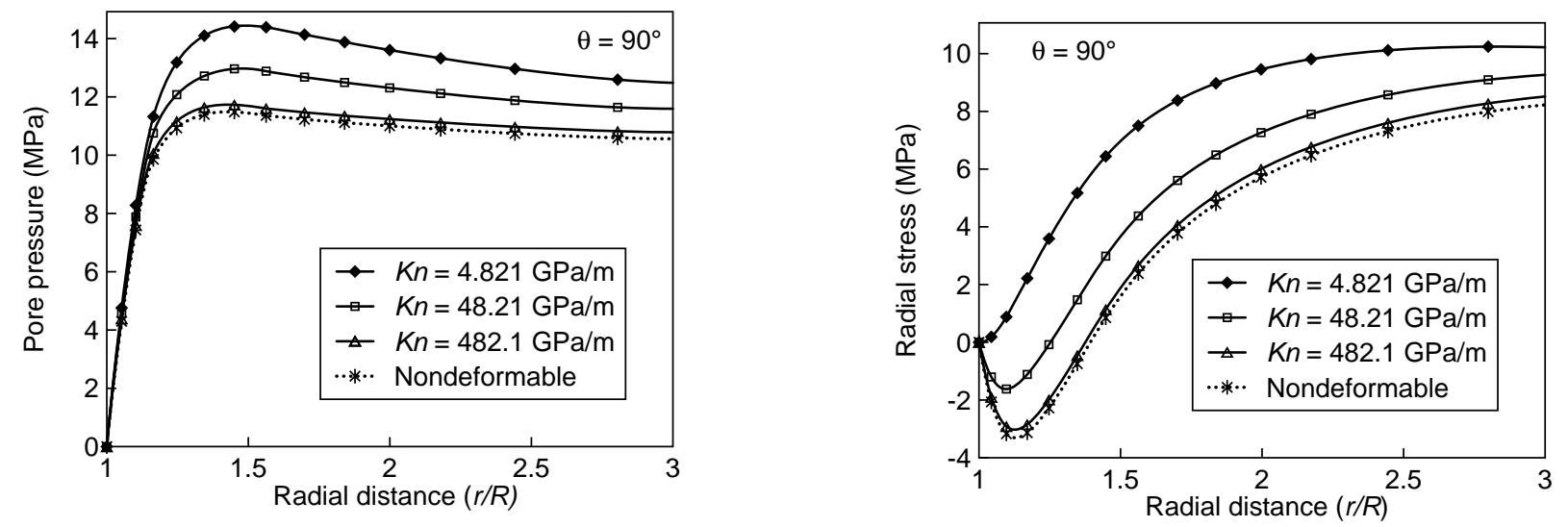

Figure 13

Pore pressure and radial stress distributions in dual-porosity poroelastic media (after Zhang, 2002). 


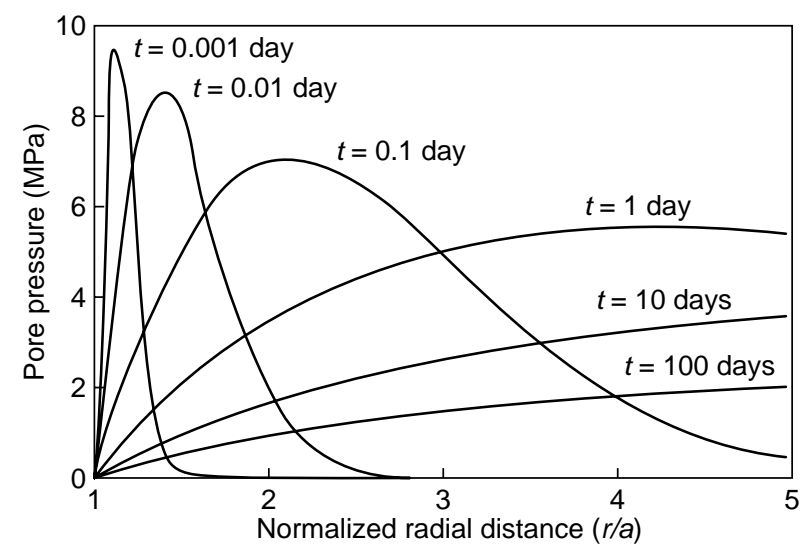

- Pore pressure peak

(1) moves away from borehole

(2) decays with time

- Pore pressure history at

a fixed location:

first goes up, then decays

- Approximate largest peak:

$0.2 \mathrm{MPa} /{ }^{\circ} \mathrm{C}$

$\left(15 \mathrm{psi} /{ }^{\circ} \mathrm{F}\right)$

Figure 14

Time-dependent pore pressure diffusion due to temperature gradient (after Li, 1999).
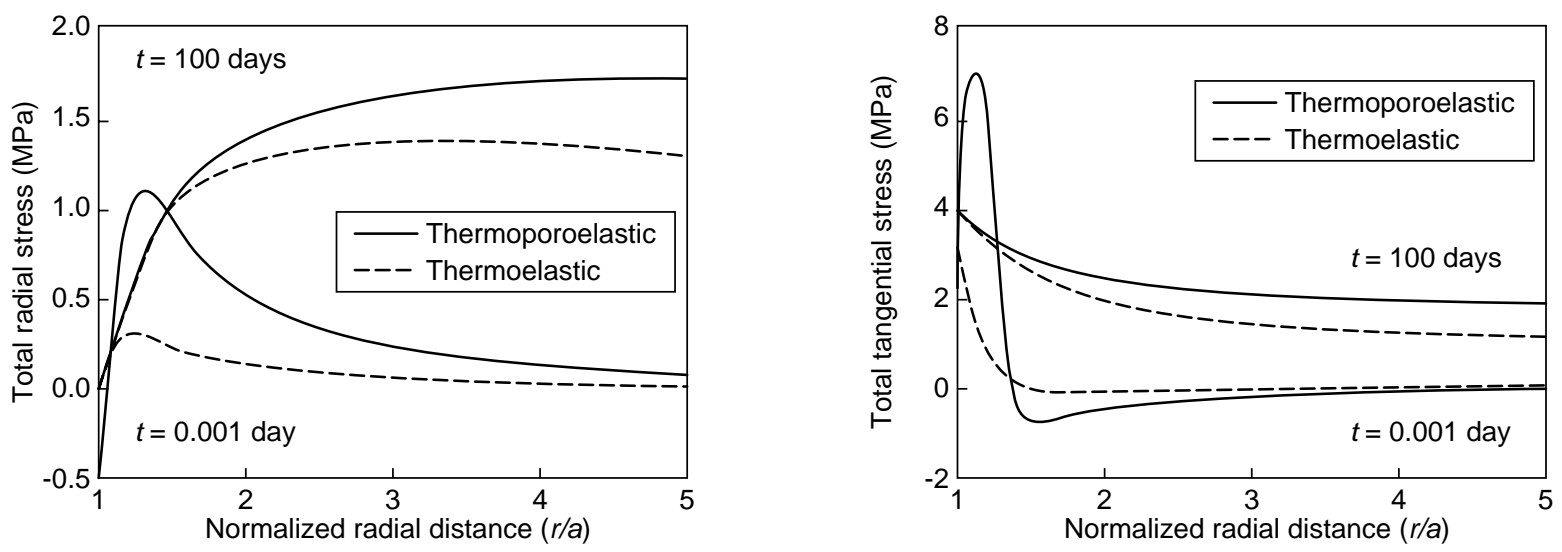

Figure 15

Radial and tangential stress distributions due to temperature gradient (after Li, 1999).
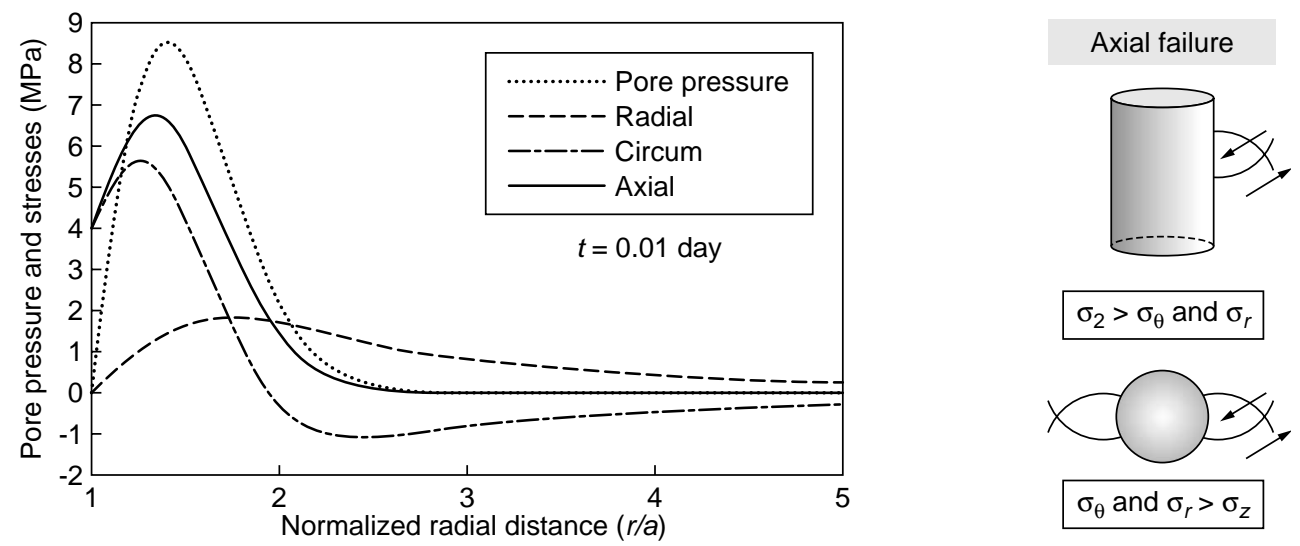

Figure 16

Pore pressure and stress distributions as a function of the radial distance for a fixed time (after $\mathrm{Li}, 1999$ ). 
Another important consequence of poroelasticity is the fact that each layer crossed by the borehole will end up with different pore pressure magnitudes, creating substantial problems when attempting to drill new boreholes in such partially depleted reservoirs; especially in interlayered shales/ sandstones sequences. Recently (Bai, 1999) introduced poroelasticity in double porosity modeling with deformable fractures and showed the importance of diffusion into fracture closing. This first order of magnitude effect influences the critical pumping rate such naturally fractured reservoirs can sustain before permanent damage occurs (refer to Figs. 12 and 13).

As far as temperature is concerned, its main effect is to affect, besides purely mechanical thermal stresses, the pore pressure magnitude. Li (1999) clearly proved that a temperature difference of $50^{\circ} \mathrm{C}$ between the mud and the reservoir created pore pressures of the order of $10 \mathrm{MPa}$ (refer to Figs. 14-16). In addition she showed that cooling the mud helped to stabilize the borehole initially, but that it increased the chances of time-dependent failure; heating the mud on the other hand enhanced the chances of failure.

\section{REFERENCES}

Germanovich, L.N. and Roegiers, J.C. (1994) A Model for Borehole Breakouts in Brittle Rocks, EURock '94, "Rock Mechanics in Pet. Eng.”. SPE/ISRM, Delft U. of Technology, The Netherlands, 361-370.

Li, X. (1999) Thermoporomechanical Modeling of Inclined Boreholes. PhD Dissertation, U. of Oklahoma.

Ong, S. -H. (1994) Borehole Stability. PhD Dissertation, U. of Oklahoma.

Santarelli, F.J., Brown, E.T. and Maury, V. (1986) Analysis of Borehole Stresses Using Pressure-Dependent, Linear Elasticity. Technical Note, Int. J. Rock Mech. Sci. \& Geomech. Abstr., 23, 6, 445-449.

Santarelli, F.J. (1987) Theorectical and Experimental Investigation of the Stability of Axisymmetric Wellbore. PhD Dissertation, U. of London.

Santarelli, F.J. and Brown, E.T. (1987) Performance of Deep Boreholes in Rocks with a Confining Pressure-Dependent Elastic Modulus. Proc. 6th Cong. Int. Soc. Rock Mech., Montreal, E, 1217-1222.

Zhang, J. (2002) Dual-Porosity Approach to Wellbore Stability in Naturally Fractured Reservoirs. PhD Dissertation, U. of Oklahoma. 